\title{
KEBERHASILAN PELAKSANAN SENAM HAMIL TERHADAP PROSES PERSALINAN
}

\author{
Vitri Yuli Afni Amran ${ }^{l}$ \\ Universitas Baiturrahmah ${ }^{l}$ \\ e-mail: 1vitriyuliafniamran@jurkeb.unbrah.ac.id ,
}

\begin{abstract}
The American College of Obstetricians and Gynecologists (ACOG) recommends exercise as a preventive measure for mothers so that the process of pregnancy and childbirth runs naturally and reduces the crisis caused by childbirth. This study aims to determine the analysis of the success rate of the implementation of pregnant exercise on the delivery process at the Puskesmas Lubuk Buaya Padang in 2018. This type of research is an analytical study with a cross-sectional approach that has been carried out in the Work Area of the Lubuk Buaya Puskesmas in Padang in October 2017 - June. 2018. The population of all mothers who have experienced childbirth in the Lubuk Buaya Padang Public Health Center is 2,042 people. Samples were taken by simple random sampling with a total sample of 48 people. Data collection using a questionnaire. Then the data were analyzed by univariate and bivariate with the chi-square statistical test. The results showed that $31.3 \%$ of mothers did not carry out pregnancy exercise correctly. As much as $37.5 \%$ of mothers gave birth with action and based on bivariate analysis there was a significant relationship between the success rate of implementing pregnancy exercise and the delivery process $(\mathrm{p}=0.000)$. The results of the study, it can be concluded that there is a relationship between the success rate of implementing pregnancy exercise with the delivery process, it is hoped that health workers will continue to provide health education and counseling and disseminate information about pregnancy exercise and empower other health workers to conduct pregnancy exercise counseling for pregnant women. how to demonstrate every pregnancy exercise movement in various pregnancy class activities so that mothers can understand it. Key words: pregnancy exercise, childbirth process, class of pregnant women
\end{abstract}

\begin{abstract}
ABSTRAK
American College of Obstetricans and Gynecologist (ACOG) merekomendasikan senam sebagai upaya preventif pada ibu agar proses kahamilan dan persalinan berjalan secara alamiah dan mengurangi krisis akibat persalinan. Penelitian ini bertujuan untuk mengetahui analisa tingkat keberhasilan pelaksanaan senam hamil terhadap proses persalinan di Puskesmas Lubuk Buaya Padang tahun 2018. Jenis penelitian ini adalah analitik dengan pendekatan yang digunakan cross sectional study yang telah dilakukan di Wilayah Kerja Puskesmas Lubuk Buaya Padang pada bulan Oktober 2017 - Juni 2018. Populasi semua ibu yang telah menghadapi proses persalinan yang ada di Wiayah Kerja Puskesmas Lubuk Buaya Padang berjumlah 2.042 orang. Sampel diambil secara simple random sampling dengan jumlah sampel sebanyak 48 orang. Pengumpulan data menggunakan kuesioner. Kemudian data dianalisis secara univariat dan bivariat dengan uji statistik chi-square. Hasil penelitian didapatkan 31,3\% ibu tidak benar dalam melaksanakan senam hamil. Sebesar 37,5\% ibu melahirkan dengan tindakan dan berdasarkan analisa bivariat terdapat hubungan yang bermakna antara tingkat keberhasilan pelaksanaan senam hamil dengan proses persalinan $(\mathrm{p}=0,000)$. Hasil penelitian maka dapat disimpulkan bahwa ada hubungan tingkat keberhasilan pelaksanaan senam hamil dengan proses persalinan, maka diharapkan kepada petugas kesehatan untuk terus memberikan pendidikan kesehatan maupun penyuluhan dan menyebarkan luaskan informasi tentang senam hamil serta memberdayakan petugas kesehatan lain untuk melakukan konseling senam hamil pada ibu hamil dengan cara mendemontrasikan setiap gerakan senam hamil dalam berbagai kegiatan kelas hamil agar ibu dapat memahaminya.
\end{abstract}

Kata kunci : senam hamil, proses persalinan, kelas ibu hamil 


\section{PENDAHULUAN}

Kehamilan merupakan proses reproduksi yang memerlukan perawatan secara khusus agar berlangsung dengan baik. Dengan terjadinya kehamilan maka wanita mengalami perubahan yang mendasar sehingga dapat menunjang perkembangan dan pertumbuhan janin dalam rahim, yang salah satunya adalah perubahan fisik selama hamil ${ }^{1}$.

Perubahan yang terjadi pada masa kehamilan tersebut mungkin dapat menjadi penyulit selama masa kehamilan maupun masa persalinan. Penyulit selama masa kehamilan maupun persalinan seperti partus lama yang dipengaruhi oleh faktor tenaga/power, jalan lahir dan janin. Adanya penyulit selama masa kehamilan dan selama masa persalinan dapat meningkatkan angka kematian ibu ${ }^{2}$

Word Health Organization (WHO) memperkirakan lebih dari 500.000 ibu meninggal karena kehamilan dan persalinan. Sedangkan di Indonesia AKI masih cukup tinggi, dimana tahun 2016 sebesar 306 per 100.000 kelahiran hidup. Melanjutkan target MDGs untuk menurunkan AKI, maka dibentuklah Sustainable Development Goals (SGDs) yang mempunyai target untuk menurunkan AKI menjadi 70 per 100.000 kelahiran hidup sampai tahun $2030^{3}$.

Pemberian pelayanan kesehatan dasar yang berkualitas diperkirakan akan dapat menurunkan AKI ${ }^{4}$, yang salah satunya adalah pelayanan prenatal. Fungsi utama pelayanan prenatal antara lain promosi kesehatan selama kehamilan melalui sarana pendidikan kesehatan, yang diberikan secara individu maupun kelompok. Materi pendidikan kesehatan untuk ibu hamil cukup banyak, salah satunya senam hamil ${ }^{5}$.

Senam hamil merupakan suatu metode yang penting untuk mempertahankan atau memperbaiki keseimbangan fisik terhadap calon ibu ${ }^{6}$. Ibu hamil yang melakukan senam hamil secara teratur selama masa kehamilannya dilaporkan dapat memberikan keuntungan pada saat persalinan yaitu pada masa kala aktif (kala II) menjadi lebih pendek, mencegah terjadinya letak sungsang dan mengurangi terjadinya insinden sectio caesaria ${ }^{1}$. Oleh karenanya American College of Obstetricans and Gynecologist (ACOG) merekomendasikan senam sebagai upaya preventif pada ibu agar proses kahamilan dan persalinan berjalan secara alamiah dan mengurangi krisis akibat persalinan $^{7}$.

Senam hamil yang memiliki manfaat sangat besar ini ternyata masih banyak tidak dipahami oleh ibu hamil, yang menyebabkan ibu hamil merasa enggan untuk mengikuti senam. Hal ini ditakutkan akan menjadi salah satu faktor penyulit proses persalinan. Kurangnya pengetahuan ibu hamil tentang senam hamil disebabkan karena rendahnya minat masyarakat terutama ibu hamil untuk mengakses informasi tentang senam hamil dan keterjangkauan informasi yang masih rendah ${ }^{8}$.
Adanya pelaksanaan senam hamil diharapkan dapat meningkatkan kunjungan ibu hamil pada pemeriksaan ibu hami, tingginya persalinan di fasilitas kesehatan dan dapat meningkatkan pemahaman ibu hamil terhadap manfaat senam hamil. Keadaan ini menjadi suatu upaya dari pemerintah dalam meningkatkan kegiatan pelaksanaan kelas ibu hamil terutama kegiatan senam hamil yang dievaluasi dengan indikator keberhasilan senam hamil. Sementara untuk merubah perilaku ibu hamil tidak dapat dilakukan dalam waktu singkat. Minimal diperlukan waktu dan paparan yang intensif untuk merubah perilaku ibu hamil berkunjung ke fasiltas kesehatan dalam mengikuti senam hamil ${ }^{9}$.

Berdasarkan data Dinas Kesehatan Propinsi Sumatera Barat tahun 2014, Angka Kematian Ibu (AKI) masih tinggi yaitu 212 per 100.000 kelahiran hidup dan ini belum tercapainya target untuk tahun 2015 sebesar 102 per 100.000 kelahiran hidup ${ }^{10}$.

\section{METODE}

Penelitian ini bersifat analitik. Penelitian ini telah dilaksanakan di Puskesmas Lubuk Buaya Padang pada bulan Oktober 2017 - Juni 2018. Populasi adalah keseluruhan objek yang diteliti atau objek penelitian (Notoatmodjo, 2012). Populasi adalah semua ibu yang telah menghadapi proses persalinan yang ada di Wiayah Kerja Puskesmas Lubuk Buaya Padang berjumlah 2.042 orang. Sampel adalah objek yang diteliti dan dianggap mewakili seluruh populasi (Notoatmodjo, 2012). Jadi jumlah sampel didapatkan sebanyak 48 orang, dengan teknik sampel adalah simple random sampling yaitu sampel diambil secara acak dengan cara undian. Analisa yang dilakukan terhadap dua variabel yang diduga berhubungan atau berkorelasi. Analisa bivariat dalam penelitian ini menggunakan uji statistik chi-square. Analisa dilakukan secara komputerisasi. Kemungkinan hubungan dapat di lihat dari nilai $\mathrm{p}$. Bila $\mathrm{p} \leq \alpha(0,05)$ maka disimpulkan ada hubungan yang bermakna antara variabel independen dengan variabel dependen (Ha diterima). Sebaliknya $\mathrm{p}>\alpha(0,05)$ maka disimpulkan tidak ada hubungan yang bermakna antara variabel independen dengan variabel dependen ( $\mathrm{Ha}$ ditolak).

\section{HASIL}

Hasil penelitian yang telah dilakukan tentang analisa tingkat keberhasilan pelaksanaan senam hamil terhadap proses persalinan di wilayah kerja Puskesmas Lubuk Buaya Padang, dengan jumlah sampel sebanyak 48 orang, maka didapatkan hasil penelitian sebagai berikut :

Tabel 1. Karakteristik Responden 


\begin{tabular}{lcc}
\hline Karakteristik & $\boldsymbol{F}$ & $\boldsymbol{\%}$ \\
\hline Umur & & \\
$<20$ tahun & 0 & 0 \\
$20-35$ tahun & 42 & 87,5 \\
$>35$ tahun & 6 & 12,5
\end{tabular}

\begin{tabular}{lll} 
Pendidikan & & \\
Rendah & 27 & 56,2 \\
Tinggi & 21 & 43,8 \\
Pekerjaan & & \\
Tidak bekerja & 23 & 47,9 \\
Bekerja & 25 & 52,1 \\
$\quad$ Jumlah & $\mathbf{4 8}$ & $\mathbf{1 0 0}$ \\
\hline
\end{tabular}

Tabel diatas menjelaskan bahwa sebagian besar $(87,5 \%)$ ibu pada umur antara 20-35 tahun,

Lebih dari separuh ibu $(56,2 \%)$ berpendidikan rendah dan lebih dari separoh $(52,1 \%)$ ibu bekerja.

Tabel 2. Keberhasilan Pelaksanaan Senam Hamil dengan Proses Persalinan

\begin{tabular}{lcccccc}
\hline \multirow{2}{*}{ Pelaksanaan } & \multicolumn{9}{c}{ Proses Persalinan } & Total & $\%$ \\
\cline { 2 - 5 } Senam Hamil & \multicolumn{2}{c}{ Tindakan } & \multicolumn{2}{c}{ Normal } & & \\
& f & $\mathbf{\%}$ & $\mathbf{f}$ & $\mathbf{\%}$ & & \\
Tidak Benar & 13 & 86,7 & 2 & 13,3 & 15 & 100 \\
Benar & 5 & 15,2 & 28 & 84,8 & 33 & 100 \\
$\quad$ Jumlah & $\mathbf{1 8}$ & $\mathbf{3 7 , 5}$ & $\mathbf{3 0}$ & $\mathbf{6 2 , 5}$ & $\mathbf{4 8}$ & $\mathbf{1 0 0}$ \\
\hline \multicolumn{1}{c}{} & & \multicolumn{5}{c}{$p$ value $=0,000$}
\end{tabular}

Tabel diatas menjelaskan bahwa ibu benar melaksanakan senam ibu hamil berhasil melahirkan dengan normal $(84,4 \%)$, sementara tindakan lebih banyak ditemukan pada ibu yang tidak benar melaksanakan senam hamil.. Berdasarkan hasil uji statistik dengan uji Chi-Square menunjukkan $p$ value $=0,000(p<0,05)$, maka Ho ditolak dan Ha diterima, berarti ada hubungan tingkat keberhasilan pelaksanaan senam hamil dengan proses persalinan di wilayah kerja Puskesmas Lubuk Buaya Padang tahun 2018. Hasil penelitian ini dapat menjelaskan bahwa senam hamil berhasil membantu ibu dalam menghadapi proses persalinan secara normal.

\section{PEMBAHASAN}

Hasil penelitian ini dapat menjelaskan bahwa senam hamil berhasil membantu ibu dalam menghadapi proses persalinan secara normal.

Ibu yang melakukan senam hamil, tentunya untuk mencapai suatu tujuan yaitu untuk memperkuat otototot panggul, memperlancar peredaran darah karena pada saat latihan akan terjadi peningkatan pasokan oksigen sehingga akan memperlancar suplai oksigen ke janin, dan ibu hamil juga akan terlatih untuk melakukan relaksasi untuk membantu memperlancar persalinan pada saat proses persalinan berlangsung ${ }^{11}$.

Analisa peneliti, terdapatnya hubungan tingkat keberhasilan pelaksanaan senam hamil dengan proses persalinan karena ibu yang telah termotivasi untuk melakukan senam hamil, maka akan berusaha melakukannya dengan baik dan benar, dengan harapan hasil yang baik. Keinginan ibu yang berasal dari kemauan sendiri bukan dari dorongan luar akan lebih menguntungkan dan memberikan keteraturan dalam melakukan senam hamil. Ibu yang melaksanakan senam hamil juga akan lebih rileks dalam melakukan persalinan secara normal karena senam hamil dapat melonggarkan persendian yang berhubungan dengan proses persalinan.

\section{KESIMPULAN}

Dari hasil yang diperoleh dalam penelitian tentang analisa tingkat keberhasilan pelaksanaan senam hamil terhadap proses persalinan di wilayah kerja Puskesmas Lubuk Buaya Padang, dapat ditarik kesimpulan bahwa terdapat hubungan tingkat keberhasilan pelaksanaan senam hamil dengan proses persalinan di wilayah kerja Puskesmas Lubuk Buaya Padang tahun $2018(\mathrm{p}=0,000)$. Saran dalam penelitian ini diharapkan kepada petugas kesehatan untuk terus memberikan pendidikan kesehatan maupun penyuluhan dan menyebarkan luaskan informasi tentang senam hamil serta memberdayakan petugas kesehatan lain untuk melakukan konseling senam hamil pada ibu hamil dengan cara mendemontrasikan setiap gerakan senam hamil diberbagai kelas hamil agar ibu dapat memahaminya..

\section{DAFTAR PUSTAKA}

1. Manuaba. 2010. Ilmu Kebidanan, Penyakit Kandungan dan KB. Jakarta: EGC

2. Hidayah, Ridhoyanti. 2008. Hubungan Faktor Internal dengan Peran Serta Ibu Hamil dalam Mengikuti Senam Hamil di Rumah Sakit Bersalin Mutiara Bunda Malang. Jurnal Keperawatan, Volume 5, Nomor 1, Januari 2014: 31 - 38 Fakultas Kedokteran Universitas Brawijaya

3. Kemenkes RI, 2016. Profil Kesehatan Indonesia Tahun 2016. Jakarta

4. Aulia, Hendarmin. 2010. Pengaruh Senam Hamil Terhadap Proses Persalinan Normal di Klinik YK Madira Palembang. Jurnal Kebidanan, Th. 42, No. 1 Januari 2010 Fakultas Kedokteran Unsri

5. Yuniastari, Annisa, Dwi. 2013. Analisis FaktorFaktor yang Berhubungan dengan Pelaksanaan Senam Hamil di Wilayah Puskesmas Purwokerto Barat. Jurnal Kesehatan Masyarakat (e-Journal), Volume 2, Nomor 5, Mei 2014. Fakultas Kesehatan Masyarakat Universitas Diponegoro

6. Maryunani, Anik dan Sukaryati, Yetti. 2012. Senam Hamil, Senam Nifas dan Terapi Musik. Jakarta: Trans Info Media

7. Widyawati dkk. 2013. Pengaruh Senam Hamil terhadap Proses Persalinan dan Status Kesehatan Neonatus di Rumah Bersalin Gratis Rumah Zakat Surabaya. Jurnal. Fakultas Kesehatan Masyarakat 
Universitas Airlangga Surabaya Jawa Timur

8. Rate, Putri, Pamungkas. 2016. Gambaran Pengetahuan Ibu Hamil tentang Senam Hamil di Puskesmas Bandarharjo Semarang. Jurnal Kebidanan Akademi Kebidanan Ngudi Waluyo

9 Fuada, Noviai. 2014. Pelaksanaan Kelas Ibu Hamil di Indonesia. Jurnal Balai Penelitian dan Pengembangan GAKI Badan Litbangkes Kemenkes

10. Dinas Kesehatan Propinsi Sumatera Barat. 2015. Profil Kesehatan Propinsi Sumatera Barat Tahun 2015. Padang

11. Yuliasari. 2010. Hubungan Pengetahuan dan Sikap dengan Pelaksanaan Senam Hamil (studi pada ibu hamil trimester II dan III) di Puskesmas Ciputat Tangerang Selatan. Skripsi 